\title{
Deli Bal Zehirlenmesi Hastalarında Elektrokardiyografi Analizi
}

\author{
Electrocardiography Analysis in Patients with Mad Honey Intoxication
}

\author{
Altuğ Ösken ${ }^{1}$, Selçuk Yaylaci ${ }^{2-3}$, Ercan Aydin ${ }^{4}$, Neşe Çam $^{1}$ \\ ${ }^{1}$ Siyami Ersek Göğüs Kalp Damar Cerrahisi Eğitim ve Araştırma Hastanesi, Kardiyoloji Bölümü, İstanbul, Türkiye \\ ${ }^{2}$ Sakarya Üniversitesi Tip Fakültesi, İç hastalıkları bölümü, Sakarya, Türkiye \\ ${ }^{3}$ Fındıkl Devlet Hastanesi, İç hastalıkları bölümü, Rize, Türkiye \\ ${ }^{4}$ Trabzon Vakfıkebir Devlet Hastanesi, Kardiyoloji Bölümü, Trabzon, Türkiye \\ Yazışma Adresi / Correspondence: \\ Altuğ Ösken \\ Siyami Ersek Göğüs Kalp Damar Cerrahisi Eğitim ve Araştırma Hastanesi, Kardiyoloji Bölümü, İstanbul, Türkiye \\ T: +90 216-542 $4444 \quad$ E-mail : alosk@hotmail.com \\ Geliş Tarihi / Received : 04.05.2021 Kabul Tarihi / Accepte: 04.06.2021 \\ Orcid:
}

Altuğ Ösken https://orcid.org/0000-0003-3018-339X

Selçuk Yaylacı https://orcid.org/0000-0002-6768-7973

Ercan Aydin https://orcid.org/0000-0001-8743-3762

Neşe Çam https://orcid.org/0000-0001-5812-1639

( Sakarya Tip Dergisi / Sakarya Med J 2021, 11(3):631-638) DOI: 10.31832/smj.932847

\footnotetext{
$\ddot{O} z$

Amaç Risk belirlemesi, prognoz tayini ve klinik gözlem açısından elektrokardiyografi (EKG) parametreleri intoksikasyon hastalarında siklkla kullanılmaktadır ve kritik öneme sahiptir. Bu çalışma deli bal zehirlenmesi (DBZ) tanısı ile takip edilen hastaların demografik, klinik özelliklerini araştırmayı ve elektrokardiyografik parametreleri analiz etmeyi amaçlamaktadır.

Gereç ve Haziran 2013 - Kasım 2014 tarihleri arasında Doğu Karadeniz Bölgesỉnde yer alan bir devlet hastanesinin acil servisinde DBZ tanısı nedeniyle takip ve tedavi edilen 68 Yöntemler hasta retrospektif çalısmamıza dahil edildi. Yas, cinsiyet, toksikolojik özellikler, laboratuvar parametreleri, kalp hızları, sistolik ve diyastolik kan basınçları, laboratuvar parametreleri, EKG verileri açısından hastalar kaydedildi ve analizleri yapıldı. EKG’de izlenen cQT (düzeltilmiș QT intervali) uzaması ve QRS genișlemesi varlığına göre hastalar ayrı ayrı gruplara ayrılarak, gruplar arası karşılaştırmalar yapıldı.

Bulgular Çalışma populasyonuna dahil edilen hasta grubunda $32(\% 47,1)$ hastada cQT uzaması, $19(\% 27,9)$ hastada ise QRS genişlemesi izlendi. Geçmiște deli bal tüketim öyküsü, tedavide kullanılan izotonik sodyum klorür miktarı ve QRS mesafesi; QT uzaması saptanan DBZ hasta grubunda anlamlı olarak yüksekti. QRS genişlemesi olan DBZ hastalarında klinik, laboratuvar değişkenler açısından farkllık gözlenmez iken, cQT açısından anlamlı farklılık mevcuttu.

Sonuç Elektrokardiyografik parametrelerden cQT uzaması ve QRS genișlemesi DBZ hastalarında sıklıkla gözlenebilmektedir. Bu hastalarda uzun dönemde atriyal ve ventriküler aritmi gelişme potansiyeli mevcut olabileceğinden klinik ve EKG takiplerinin düzenli yapılması uygun olacaktır.

Anahtar deli bal zehirlenmesi; elektrokardiyografi; ritim bozukluğu

Kelimeler

Abstract

Objective Electrocardiography (ECG) parameters are frequently used in intoxication patients and have critical importance in terms of risk stratification, prognosis determination and clinical observation. This study aims to investigate the demographic and clinical characteristics and to analyze the electrocardiographic parameters of patients with mad honey intoxication (MHI).

Materials 68 patients who were followed up and treated with MHI in the emergency department of a state hospital in the Eastern Black Sea Region between June 2013 and November 2014 were included and Methods in our retrospective study. The patients were recorded and analyzed in terms of age, gender, clinical characteristics, laboratory parameters, heart rates, systolic and diastolic blood pressures and electrocardiography (ECG) data. Patients were divided into separate groups according to the presence of cQT (corrected QT interval) prolongation and QRS widening observed on the ECG, and comparisons between groups were made.

Resulrs In the patient group included in the study population, 32 (47.1\%) patients had cQT prolongation and 19 (27.9\%) patients had QRS widening. History of mad honey consumption, amount of isotonic sodium chloride used in treatment and QRS duration was significantly higher in the patient group with MHI and QT prolongation. While there was no difference in clinical and laboratory variables in MHI patients with QRS enlargement, there was a significant difference in terms of $c Q T$.

Conclusion Among the electrocardiographic parameters, $C$ QT prolongation and QRS enlargement can be observed frequently in MHI patients. Since these patients may have the potential to develop atrial and ventricular arrhythmias in the long term, regular clinical and ECG follow-ups would be appropriate.

Keywords arrhythmia; electrocardiography; mad honey intoxication
} 


\section{GIIRIŞ}

Deli bal zehirlenmesi (DBZ), ülkemizde sıklıkla Doğu Karadeniz bölgesinde yetişen Rhododendron Ponticum ve Luteum familyasına ait bitkilerden elde edilen balın tüketilmesiyle oluşur. ${ }^{1}$ İnsanlarda zehirlenmeden sorumlu toksin Grayonotoksin (GTx)'dir. Tanımlanmış 18 adet GTx bulunmakla birlikte GTx I, GTx II ve GTx III asıl toksik etkilerden sorumlu tutulmuştur. ${ }^{2}$ Potansiyel kardiyak yan etkilerden sorumlu olan GTx II'dir. GTx II, hücre membranındaki sodyum ( $\mathrm{Na}$ ) kanallarına bağlanarak $\mathrm{Na}$ kanal inaktivasyonunu önler, membran geçirgenliğini arttırır, repolarizasyonu inhibe ederek membran potansiyelini hiperpolarizasyon safhasinda tutar ve sinoatrial nodun spontan atımlarını baskılar. ${ }^{3}$ Grayanotoksinler kardiyovasküler, santral sinir sistemi, solunum ve gastrointestinal sistemleri etkileyebilir. Semptomlar arasında ağızda ve yutakta yanma hissi, anoksi, tükürük salgısı, kusma, kas güçsüzlüğü, görme keskinliğinde azalma ve bradikardi, ardından şiddetli hipotansiyon, solunum felci, koma ve ölüm yer alır. ${ }^{4}$

DBZ tanısında ve yüksek riskli hastaların belirlenmesinde elektrokardiyografi (EKG) şüphesiz kritik bir öneme sahiptir. Erken teşhis ve etkin tedavi ile komplikasyon oranları kolaylıkla azaltılabilir. DBZ ile tetiklenen pek çok EKG değişikliği literatürde tanımlanmıştır. ${ }^{5-8}$ Sodyum kanal blokajının neden olduğu zehirlenme vakalarında; QRS süresi, QT intervali uzunluğu ve atriyal-ventriküler depolarizasyon-repolarizasyon parametrelerinde değişiklikler gözlenmiştir.9,10 Şimdiye kadar çok az çalışma, intoksikasyon hastalarında EKG parametrelerini değerlendirmiş olsa da, henüz DBZ’nin hastaların ventriküler EKG parametreleri üzerindeki etkilerini inceleyen bir çalışma yoktur. Bu nedenle, bu çalışmayı DBZ hastalarında ventrikül içi iletimin ve repolarizasyon parametrelerinin bozulabileceği hipotezine dayanarak gerçekleştirdik. Bu çalışmada, DBZ ile acil servislere başvuran hastalarda ayrıntılı EKG parametrelerini değerlendirmeye ve QT uzaması ile QRS genişlemesi sıklığını belirlemeye çalıştık.

\section{GEREÇ ve YÖNTEMLER}

Çalışmamız kesitsel tipte tanımlayıcı araştırma olarak tasarlandı ve Sakarya Üniversitesi Etik Kurulu'ndan onam alındı (etik komite onay tarihi: 29.01.2021, onay no: 604624). Ülkemizin Doğu Karadeniz bölgesinde yer alan bir ilçe devlet hastanesinde Haziran 2013 - Kasım 2014 tarihleri arasında DBZ nedeniyle takip ve tedavi edilen 112 hastanın verileri retrospektif olarak analiz edildi. Önceden teşhis edilmiş iskemik veya kalp kapak hastalığı, kronik böbrek yetmezliği, tiroid hastalığı, elektrolit dengesizliği olan hastalar; antiaritmik ilaçlar veya QT uzamasına yol açabilecek ilaç kullananlar; EKG'de sinüs bradikardisi d1şında başka özellikleri olanlar (örn. tam atriyoventriküler blok, ST yükselmesi depresyonu, atriyal fibrilasyon, atriyal-ventriküler erken atımlar) çalışma dışında bırakıldı.

Hastalarda, DBZ tanısı şu kriterlere göre konuldu: işlenmemiş, yerel olarak elde edilen balın tüketimi sonrası baş dönmesi, bulantı/kusma, bulanık görme, bilinç değişikliği semptomlarının gelişmesi; fizik muayenede hipotansiyon ve bradikardi gözlenmesi ve EKG'de bradiaritminin izlenmesi. Hastalar sıklıkla 0,5 mg atropin, $1 \mathrm{mg}$ atropin ve salin (iv izotonik sodyum klorür) ile tedavi edildi ve genellikle hastalar klinik iyileşmeden sonraki ilk 24 saat içinde taburcu edildi.

Hastaların demografik verileri, klinik semptomları, tüketilen bal miktarı (kaşık başına), bal tüketimi sonrası acil servis başvurusuna kadar geçen süre, semptomların tamamen ortadan kalkmasına kadar geçen süre ve hastanede kalış süresi, başvuru ve klinik takip sırasında kaydedildi. EKG verileri analiz için uygun olmayan ve dışlama kriterlerini içeren 44 hastanın çıkartılmasından sonra 68 hasta ile son analiz yapıldı.

\section{EKG parametrelerinin değerlendirilmesi}

Acil serviste DBZ ön tanısıyla ilk başvuru esnasında çekilen on iki derivasyonlu istirahat EKG'leri incelendi ve analiz edildi. Tüm EKG’ler 25 ila 50 mm / s kağıt hızında ve 1 ila $2 \mathrm{mV} / \mathrm{cm}$ kalibrasyon seviyesinde kaydedildi. Daha güvenilir değerlendirme ve ölçümlerin kolaylaştırılması 
için kaydedilen EKG'ler tarandı ve bir dijital medya platformuna aktarıldı; daha sonra, hesaplamalar tecrübeli bir kardiyolog tarafından offline analiz ile yapıldı.

QRS süresi, EKG cihazı yazılımı kullanılarak hesaplandı. Her iki ventrikülün elektriksel depolarizasyonunu / repolarizasyonunu temsil eden QT intervali sıklıkla D2 derivasyonu kullanılarak hesapland1, V5 veya V6 derivasyonları alternatif olarak kullanıldı. QRS’nin başlangıcından T dalgasının sonuna kadar ölçülmesi ile hesaplandı. QT'yi kalp hızına göre ayarlamak ve düzeltilmiş QT'yi (cQT) elde etmek için önerilen formüllerden en sık tercih edilen Bazzet'in formülü (QT / $\sqrt{ }$ RR) kullanılarak cQT hesapland $1 .{ }^{11}$ Erkeklerde cQT'nin $450 \mathrm{~ms}$, kadınlarda ise 470 ms'nin üzerinde olması cQT uzaması olarak kabul edildi. QRS süresinin 100 ms'nin üzerinde olması QRS genişlemesi olarak kabul edildi. Tüm çalışma populasyonunun demografik, laboratuvar ve bazal EKG verileri değerlendirildi. Ardından hastalar cQT uzaması ve QRS genişlemesi varlığına göre gruplara ayrılarak gruplar arası karşılaştırmalar yapildi.

\section{İstatistiksel analiz}

Hasta verileri üzerinde istatistiksel analiz yapmak için SPSS 20.0 yazılım programı (SPSS Inc., Chicago, IL, ABD) kullanıldı. Kategorik değişkenler sayılar veya yüzdeler ile, sürekli değişkenler ise ortalama \pm standart sapma olarak ifade edildi. Kategorik değişkenlerin karşılaştırılmasında Ki-kare testi ve Fisher's Exact test kullanıldı. Sürekli değişkenlerin karşılaştırılmasında ilk olarak parametrelerin normal dağılımını test etmek için Kolmogorov-Smirnov testi yapıldı. Normal dağılıma uyan verileri karşılaştırmak için bağımsız örneklem t-testi kullanıldı. Normal dağılıma uymayan değişkenler için Mann Whitney u testi kullanıldi. $\mathrm{p}<0,05$ değeri istatistiksel olarak anlamlı kabul edildi.

\section{BULGULAR}

Çalışmamıza DBZ ile takip edilen 68 hasta [54 erkek, \% $79,4]$ dahil edildi ve ortalama yaş $52,2 \pm 15,8$ idi. Genel çalışma populasyonun demografik bulguları, klinik verileri, laboratuar ve EKG parametreleri Tablo 1'de gösterilmektedir.

\begin{tabular}{|c|c|}
\hline & $\begin{array}{l}\text { Çalışma Populasyonu } \\
\qquad(\mathrm{n}=68)\end{array}$ \\
\hline Yaş, (Ort $\pm S S)$ & $52,2 \pm 15,8$ \\
\hline Cinsiyet, Erkek, n (\%) & $54(79,4)$ \\
\hline Hipertansiyon, n (\%) & $21(30,9)$ \\
\hline Diyabet, n (\%) & $14(20,6)$ \\
\hline Sigara, n (\%) & $19(27,9)$ \\
\hline Sistolik kan basınc1, $\mathrm{mmHg}(\mathrm{Ort} \pm \mathrm{SS})$ & $82,6 \pm 13,5$ \\
\hline Diastolik kan basınc1, mmHg (Ort \pm SS) & $50,6 \pm 9,8$ \\
\hline Bal tüketim miktarı (kaşı) (Ort $\pm S S)$ & $3,8 \pm 1,2$ \\
\hline Öncesinde tüketim öyküsü, n (\%) & $19(27,9)$ \\
\hline Semptom başlangıcı (saat), (Ort \pm SS) & $0,93 \pm 0,9$ \\
\hline Semptom süresi (saat), (Ort $\pm S S)$ & $1,05 \pm 0,26$ \\
\hline Hastanede kalış süresi (saat), (Ort \pm SS) & $5,62 \pm 1,45$ \\
\hline $\begin{array}{l}\text { Serum (izotonik) miktarı (ml), (Or- } \\
\mathrm{t} \pm \mathrm{SS})\end{array}$ & $882,3 \pm 357,4$ \\
\hline Atropin $(\mathrm{mg}),(\mathrm{Ort} \pm \mathrm{SS})$ & $0,76 \pm 0,62$ \\
\hline Baş dönmesi, n (\%) & $58(85,3)$ \\
\hline Bulant1/kusma, n (\%) & $54(79,4)$ \\
\hline Şuur bulanıklığı, n (\%) & $20(29,4)$ \\
\hline Bilinç kaybı, n (\%) & $13(19,1)$ \\
\hline Glukoz, mg/dL, (Ort \pm SS) & $101,1 \pm 42$ \\
\hline Kan üre azotu, mg/dl, (Ort $\pm S S)$ & $19,3 \pm 5,7$ \\
\hline Kreatinin, mg/dL, (Ort $\pm S S)$ & $1,09 \pm 0,21$ \\
\hline $\begin{array}{l}\text { Kreatinin Kinaz Myokardial Band, } \\
\text { U/L, (Ort } \pm \text { SS) }\end{array}$ & $2,82 \pm 2,21$ \\
\hline Troponin I, ng/mL, (Ort \pm SS) & $0,004 \pm 0,006$ \\
\hline Sodyum, mEq/L, (Ort $\pm \mathrm{SS})$ & $140,8 \pm 3,8$ \\
\hline Potasyum, $\mathrm{mEq} / \mathrm{L},(\mathrm{Ort} \pm \mathrm{SS})$ & $4,3 \pm 0,5$ \\
\hline Hemoglobin, g/dl, (Ort $\pm S S)$ & $12,86 \pm 1,72$ \\
\hline Lökosit, x109/L, (Ort $\pm S S)$ & $6,94 \pm 1,66$ \\
\hline Platelet, $x 109 / \mathrm{L},(\mathrm{Ort} \pm \mathrm{SS})$ & $213 \pm 58$ \\
\hline Kalp hızı (dk), (Ort $\pm S S)$ & $44,9 \pm 6,9$ \\
\hline QRS mesafesi (msn), (Ort \pm SS) & $94,5 \pm 11,6$ \\
\hline QT (msn), (Ort \pm SS) & $410,5 \pm 36,7$ \\
\hline QTc (msn), (Ort \pm SS) & $458,9 \pm 39,3$ \\
\hline QT uzaması, n (\%) & $32(47,1)$ \\
\hline QRS genișlemesi, n (\%) & $19(27,9)$ \\
\hline
\end{tabular}

Tüm hasta grubunda, QT uzaması $32(\% 47,1)$ hastada, 
QRS genişliği ise $19(\% 27,9)$ hastada gözlenmiştir. Tablo 2'de QT uzaması olan ve olmayan hastaların demografik bulguları, klinik verileri, laboratuar ve EKG parametrelerinin karşılaştırılması gösterilmektedir. Önceden deli bal tüketim öyküsü, tedavide kullanılan serum (izotonik) miktarı ve QRS mesafesi, cQT uzaması olan grupta an- lamlı olarak yüksek bulunmuştur. Tablo 3’te ise QRS genişlemesi olan ve olmayan hastalar karşılaştırılmıştır. QT ve cQT interval uzunluğu QRS genişlemesi olan grupta anlamlı olarak yüksek iken diğer parametrelerde anlamlı farklılık saptanmamıştır.

\section{TARTIŞMA}

\begin{tabular}{|c|c|c|c|}
\hline Characteristics & $\begin{array}{l}\text { QT uzamasi }(+) \\
(\mathrm{n}=32)\end{array}$ & $\begin{array}{l}\text { QT uzaması }(-) \\
(\mathrm{n}=36)\end{array}$ & $P$ value \\
\hline Yaş, (Ort $\pm S S)$ & $56,1 \pm 16,8$ & $48,8 \pm 14,22$ & 0,060 \\
\hline Cinsiyet, Erkek, n (\%) & $27(84,4)$ & $27(75)$ & 0,340 \\
\hline Hipertansiyon, n (\%) & $8(25)$ & $13(36,1)$ & 0,322 \\
\hline Diyabet, n (\%) & $8(25)$ & $6(16,7)$ & 0,396 \\
\hline Sigara, n (\%) & $12(37,5)$ & $7(19,4)$ & 0,098 \\
\hline Sistolik kan basınc1, mmHg (Ort \pm SS) & $80,63 \pm 15,85$ & $84,44 \pm 11,07$ & 0,260 \\
\hline Diastolik kan basınc1, mmHg (Ort \pm SS) & $49,06 \pm 11,46$ & $51,94 \pm 7,86$ & 0,238 \\
\hline Bal tüketim miktarı (kaşı) (Ort $\pm S S)$ & $3,88 \pm 1,28$ & $3,72 \pm 1,16$ & 0,277 \\
\hline Öncesinde tüketim öyküsü, n (\%) & $13(40,6)$ & $6(16.7)$ & 0,028 \\
\hline Semptom başlangıcı (saat), (Ort \pm SS) & $0,98 \pm 0,3$ & $0,88 \pm 0,21$ & 0,685 \\
\hline Semptom süresi (saat), (Ort \pm SS) & $1,06 \pm 0,27$ & $1,04 \pm 0,25$ & 0,745 \\
\hline Hastanede kalış süresi (saat), (Ort \pm SS) & $5,88 \pm 1,6$ & $5,39 \pm 1,29$ & 0,318 \\
\hline Serum (izotonik) miktarı (ml), (Ort \pm SS) & $984,38 \pm 391,11$ & $791,67 \pm 301,78$ & 0,025 \\
\hline Atropin (mg), (Ort $\pm S S)$ & $0,71 \pm 0,63$ & $0,80 \pm 0,62$ & 0,572 \\
\hline Baş dönmesi, n (\%) & $26(81,3)$ & $32(88,9)$ & 0,375 \\
\hline Bulant1/kusma, n (\%) & $28(87,5)$ & $26(72,2)$ & 0,120 \\
\hline Şuur bulanıklığı, n (\%) & $13(40,6)$ & $7(19,4)$ & 0,056 \\
\hline Bilinç kaybı, n (\%) & $9(28,1)$ & $4(11,1)$ & 0,075 \\
\hline Glukoz, mg/dL, (Ort \pm SS) & $110,75 \pm 57,88$ & $92,69 \pm 16$ & 0,077 \\
\hline Kan üre azotu, mg/dl, (Ort \pm SS) & $18,91 \pm 7,16$ & $18,44 \pm 4,31$ & 0,745 \\
\hline Kreatinin, mg/dL, (Ort $\pm S S)$ & $1,08 \pm 0,17$ & $1,12 \pm 0,22$ & 0,445 \\
\hline Kreatinin Kinaz Myokardial Band, U/L, (Ort \pm SS) & $2,68 \pm 2,31$ & $2,94 \pm 2,15$ & 0,640 \\
\hline Troponin I, ng/mL, (Ort \pm SS) & $0,003 \pm 0,005$ & $0,004 \pm 0,006$ & 0,872 \\
\hline Sodyum, mEq/L, (Ort \pm SS) & $141,47 \pm 3,1$ & $140,22 \pm 4,38$ & 0,185 \\
\hline Potasyum, mEq/L, (Ort $\pm \mathrm{SS})$ & $4,24 \pm 0,47$ & $4,36 \pm 0,53$ & 0,321 \\
\hline Hemoglobin, g/dl, (Ort $\pm S S)$ & $13,03 \pm 2$ & $12,72 \pm 1,43$ & 0,473 \\
\hline Lökosit, x109/L, (Ort \pm SS) & $7,19 \pm 1,83$ & $6,71 \pm 1,49$ & 0,242 \\
\hline Platelet, x109/L, (Ort \pm SS) & $211 \pm 60$ & $214 \pm 56$ & 0,846 \\
\hline Kalp hızı (dk), (Ort \pm SS) & $43,93 \pm 8,42$ & $46,63 \pm 5,42$ & 0,117 \\
\hline QRS mesafesi (msn), (Ort \pm SS) & $98,46 \pm 13,91$ & $91 \pm 7,85$ & 0,007 \\
\hline QT (msn), (Ort \pm SS) & $434,5 \pm 34,84$ & $389,16 \pm 22,44$ & - \\
\hline QTc (msn), (Ort \pm SS) & $491,96 \pm 29,08$ & $429,66 \pm 18,29$ & - \\
\hline
\end{tabular}




\begin{tabular}{|c|c|c|c|}
\hline Characteristics & $\begin{array}{l}\text { QRS genişlemesi }(+) \\
(\mathrm{n}=19)\end{array}$ & $\begin{array}{l}\text { QRS genişlemesi (-) } \\
(\mathrm{n}=49)\end{array}$ & $P$ value \\
\hline Yaş, (Ort \pm SS) & $50 \pm 17,2$ & $53,1 \pm 15,3$ & 0,466 \\
\hline Cinsiyet, Erkek, n (\%) & $16(84,2)$ & $38(77,6)$ & 0,542 \\
\hline Hipertansiyon, n (\%) & $6(31,6)$ & $15(30,6)$ & 0,938 \\
\hline Diyabet, n (\%) & $4(21,1)$ & $10(20,4)$ & 0,953 \\
\hline Sigara, n (\%) & $5(26,3)$ & $14(28,6)$ & 0,852 \\
\hline Sistolik kan basınc1, $\mathrm{mmHg}(\mathrm{Ort} \pm \mathrm{SS})$ & $82,11 \pm 13,57$ & $82,86 \pm 13,69$ & 0,839 \\
\hline Diastolik kan basınc1, $\mathrm{mmHg}$ (Ort $\pm \mathrm{SS})$ & $49,47 \pm 9,7$ & $51,02 \pm 9,84$ & 0,561 \\
\hline Bal tüketim miktarı (kaşık) (OrtıSS) & $4 \pm 1,24$ & $3,71 \pm 1,2$ & 0,389 \\
\hline Öncesinde tüketim öyküsü, n (\%) & $6(31,6)$ & $13(26,5)$ & 0,677 \\
\hline Semptom başlangıcı (saat), (Ort \pm SS) & $1,21 \pm 0,66$ & $0,82 \pm 0,24$ & 0,116 \\
\hline Semptom süresi (saat), (Ort $\pm S S)$ & $1,05 \pm 0,22$ & $1,05 \pm 0,27$ & 0,982 \\
\hline Hastanede kalış süresi (saat), (Ort \pm SS) & $5,42 \pm 0,96$ & $5,69 \pm 1,61$ & 0,492 \\
\hline Serum (izotonik) miktarı $(\mathrm{ml}),(\mathrm{Ort} \pm \mathrm{SS})$ & $947,37 \pm 404,65$ & $857,1 \pm 338,5$ & 0,354 \\
\hline Atropin $(\mathrm{mg}),(\mathrm{Ort} \pm \mathrm{SS})$ & $0,65 \pm 0,47$ & $0,80 \pm 0,67$ & 0,385 \\
\hline Baş dönmesi, n (\%) & $14(73,7)$ & $44(89,8)$ & 0,092 \\
\hline Bulant1/kusma, n (\%) & $15(78,9)$ & $39(79,6)$ & 0,120 \\
\hline Şuur bulanıklığı, n (\%) & $7(36,8)$ & $13(26,5)$ & 0,402 \\
\hline Bilinç kaybı, n (\%) & $3(15,8)$ & $10(20,4)$ & 0,664 \\
\hline Glukoz, mg/dL, (Ort \pm SS) & $115,53 \pm 73,88$ & $95,63 \pm 17,47$ & 0,080 \\
\hline Kan üre azotu, mg/dl, (Ort \pm SS) & $18,47 \pm 5,80$ & $18,73 \pm 5,84$ & 0,869 \\
\hline Kreatinin, mg/dL, (Ort $\pm S S)$ & $1,08 \pm 0,17$ & $1,12 \pm 0,22$ & 0,858 \\
\hline Kreatinin Kinaz Myokardial Band, U/L, (Ort \pm SS) & $3,28 \pm 2,84$ & $2,64 \pm 1,93$ & 0,314 \\
\hline Troponin I, ng/mL, (Ort \pm SS) & $0,006 \pm 0,009$ & $0,002 \pm 0,003$ & 0,093 \\
\hline Sodyum, $\mathrm{mEq} / \mathrm{L},(\mathrm{Ort} \pm \mathrm{SS})$ & $140,32 \pm 3,56$ & $141 \pm 3,98$ & 0,516 \\
\hline Potasyum, mEq/L, (Ort $\pm \mathrm{SS})$ & $4,27 \pm 0,53$ & $4,32 \pm 0,5$ & 0,718 \\
\hline Hemoglobin, g/dl, (Ort $\pm S S)$ & $12,58 \pm 2,18$ & $12,97 \pm 1,51$ & 0,402 \\
\hline Lökosit, x109/L, (Ort $\pm S S)$ & $6,95 \pm 1,96$ & $6,93 \pm 1,55$ & 0,959 \\
\hline Platelet, x109/L, (Ort $\pm S S)$ & $198 \pm 41$ & $218 \pm 62$ & 0,203 \\
\hline Heart rate $(\mathrm{dk}),(\mathrm{Ort} \pm \mathrm{SS})$ & $46,21 \pm 8,55$ & $45,04 \pm 6,47$ & 0,544 \\
\hline QRS mesafesi (msn), (Ort \pm SS) & $108,57 \pm 11,58$ & $89,06 \pm 5,55$ & - \\
\hline QT (msn), (Ort \pm SS) & $430,89 \pm 41,19$ & $402,59 \pm 31,80$ & 0,004 \\
\hline QTc (msn), (Ort \pm SS) & $482,89 \pm 36,49$ & $449,71 \pm 36,7$ & 0,001 \\
\hline
\end{tabular}


DBZ tanısı ile takip ve tedavi edilen hastalarda başvuru esnasında çekilen EKG’nin detaylı değerlendirilebilmesi amacıyla yaptığımız retrospektif çalışmamızda; genel hasta grubunda cQT uzaması ve QRS genişlemesi sıklığında artış gözlemledik. Ayrıca EKG'de saptanan cQT uzaması ve QRS genişlemesi varlığına göre hastaları ayrı ayrı analiz ettiğimizde; hasta grupları arasında semptom ve klinik bulguların ciddiyeti ve laboratuar parametreleri açısından anlamlı farklılık bulunmamakla birlikte, cQT uzaması olanlarda geçmişte bal yeme öyküsünün daha sık olduğunu ve tedavide daha fazla miktarda izotonik replasmanı kullanıldığını gözlemledik.

Toksikoloji pratiğinde; hastaların değerlendirilmesi ve yönetiminde, tarama, tanı, prognoz tayini, tedaviye rehberlik etmek ve klinik ilerleyişi kaydetmek açısından EKG kritik öneme sahiptir. İlaç intoksikasyonları ve gıda zehirlenmelerinde EKG değişiklikleri izlenebilir.

DBZ hastalarında baskın semptomlar kardiyovasküler ve santral sinir sistemi tutulumu ile karakterize olmakla birlikte, gastrointestinal ve solunum sistemi irritasyonu da görülebilmektedir. ${ }^{12}$ Kardiyovasküler hemodinamik olaylardan sorumlu olan GTX II, Na kanalları üzerinde etki göstermektedir. ${ }^{3}$

Voltaj kapılı Na kanallarını bloke eden ilaçlarla zehirlenme, intraventriküler iletim kusurları, miyokardiyal depresyon, bradikardi ve ventriküler aritmilere neden olabilir. ${ }^{13}$ DBZ olan hastaların kanındaki GTX seviyelerini araştırmak, toksisitenin kardiyak yan etki boyutunu gösterebilmek açısından önemlidir. Choi ve arkadaşlarının 6 hastalık küçük bir hasta grubunda olgu bazlı yaptıkları bir çalışmada hipotansiyon ciddiyeti ile toksin miktarındaki ilişki gösterilmiştir. Fakat literatürde, kandaki toksin miktarı ile semptom ve bulguların ciddiyeti arasındaki ilişkiyi net olarak gösteren geniş hasta katılımlı bir çalışma bulun-

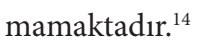

QT uzaması hayatı tehdit eden aritmilere zemin oluştura- bileceği için erken dönemde teşhis ve tedavi edilmelidir. QT uzaması genellikle ilaca bağlı sık görülmekle birlikte gıda intoksikasyonu durumlarında da izlenebilmektedir. ${ }^{15,16}$ Ayrıca vaka bazında DBZ sonrası QT uzaması da gösterilmiştir. ${ }^{17}$ Hasta grubumuzun \%47'sinde QT uzamas1 saptand1, hastalardaki ciddi bradiaritmilerin etkisi ile QT uzaması sıklığının bu denli yüksek olduğunu düşünmekteyiz. Atropin ve izotonik sodyum klorür tedavisi ile hastalarımızın hepsinde semptomlar geriledi ve kalp hızı seviyeleri normale döndü. Hastalarımızın hiçbirinde QT uzaması sonrası malign ventriküler aritmi saptanmadı.

Toksikolojide, ilaç zehirlenmeleri sonrası en sık bildirilen patolojik EKG değişikliklerinden birisi intraventriküler iletinin gecikmesi ile bulgu veren QRS genişlemesidir. ${ }^{18}$ En sık suicid amaçlı trisiklik antidepresan ilaçların kötüye kullanımı sonucu $\mathrm{Na}$ kanal blokajına bağlı olarak QRS genişlemesi oluşur. ${ }^{19}$ DBZ sonrası QRS genişlemesi ile ilgili literatür bilgisi bulunmamaktadır. Her ne kadar hastalarımızın DBZ öncesi eski EKG’lerinde QRS genişlemesi olup olmaması durumunu bilemesek de GTX'in Na kanalları üzerindeki etkisine bağlı olarak hastalarımızda QRS genişlemesi oluşabileceği tezini savunmaktayız. QRS genişlemesi olan hasta oranımız \%27,9'du ve bu hastalarda demografik, semptom ciddiyeti ve laboratuar verileri açısından anlamlı bir farklılık gözlemlemedik.

\section{Çalışmanın kısıtlılıkları}

Çalışmamızın bazı önemli kısıtlılıkları mevcuttur. Major kısıtlılık, çalışmamızın retrospektif tasarlanmasıdır. Hastaların klinik özgeçmişleri bilinmesine rağmen eski EKG bilgileri erişilebilir durumda olmadığından önemli bir kısıtlılık oluşmuştur. Ayrıca, tedavi sonrası rutin EKG değerlendirmesi yapılmadığından, EKG’deki QT uzamasının ve QRS genişlemesinin normale dönüp dönmediğini tahmin edemiyoruz. DBZ hastalarında rutin olarak kandaki GTX seviyelerini tespit etmememiz de çalışmamızın kısıtlılıklarından birisidir. Kandaki toksin seviyeleri ile kardiyak semptom ciddiyeti arasındaki ilişkiyi gösterebilecek bir çalışmanın ve DBZ hastalarında daha geniş kapsamlı, uzun 
dönem takip sonuçlarının yer aldığı gözlemsel çalışmaların literatüre önemli derecede katkı sağlayacağını düşünmekteyiz.

\section{SONUÇ}

Acil serviste erken teşhis ve tedavi, DBZ hastalarında morbidite ve mortaliteyi azaltmak için kritik öneme sahiptir. DBZ olgularında ventriküler EKG parametrelerindeki değiş̧iklikleri gözlemlemek mümkündür. Deli bal tüketimini takiben EKG değişiklikleri gösteren hastaların etkin yönetimi, kardiyak aritmilerin yaşamı tehdit edici hale gelmesini engelleyebilmek açısından önemlidir. Dahası, uzamış bradikardi ve artmış QT intervalleri olan hastalarda malign ventriküler aritmilere dönüş gözlenebileceğinden dikkatli olunmalıdır.

\section{Çıkar Çatışması Beyanı}

Yazarlar çıkar çatışması olmadığını beyan eder.

\section{Finansman}

$\mathrm{Bu}$ araştırma; kamu, ticari, özel veya kar amacı gütmeyen sektörlerdeki herhangi bir finansman kuruluşundan belirli bir hibe almadi.

\section{Yazar katkısı}

Tüm yazarlar şunlara katkıda bulunmuştur: (1) kavram ve tasarıma veya verilerin elde edilmesine veya verilerin analizine ve yorumlanmasına önemli katkılar, (2) makalenin taslağının hazırlanması veya içerik açısından eleştirel olarak revize edilmesi ve, (3) son onay yayınlanacak sürüm.

\section{Etik kurul onamı}

Sakarya Üniversitesi etik kurulu tarafından 29.01.2021

tarihinde 6046-24 onay numarası ile araştırmamız onaylanmıştır. 
Sakarya Tip Dergisi 2021;11(3):631-638

ÖSKEN ve Ark., Deli Bal Zehirlenmesinde Elektrokardiyografi

\section{Kaynaklar}

1. Gunduz A, Bostan H, Turedi S, Nuhoğlu I, Patan T. Wild flowers and mad honey. Wilderness Environ Med. 2007;18:69-71.

2. Hodgson E. Chapter Fourteen - Toxins and Venoms. Progress in Molecular Biology and Translational Science. 2012;112:373-415.

3. Nakao M, Seyama I. Effect of alpha-dihydro-grayanotoxin-II on the electrical activity of the rabbit sino-atrial node. J Physiol. 1984;357:79-91.

4. Jansen SA, Kleerekooper I, Hofman ZL, Kappen IF, StaryWeinzinger A, van der Heyden MA. Grayanotoxin poisoning: "mad honey disease" and beyond. Cardiovasc Toxicol 2012;12:208-15.

5. Okuyan E, Uslu A, Ozan Levent M. Cardiac effects of "mad honey": a case series. Clin Toxicol (Phila). 2010;48:528-32.

6. Eller P, Hochegger K, Tancevski I, Pechlaner C, Patsch JR. Sweet heart block. Circulation. 2008;118:319.

7. Dubey L, Maskey A, Regmi S. Bradycardia and severe hypotension caused by wild honey poisoning. Hellenic J Cardiol. 2009;50:426-8.

8. Aliyev F, Türkoglu C, Celiker C. Nodal rhythm and ventricular parasystole: an unusual electrocardiographic presentation of mad honey poisoning. Clin Cardiol. 2009;32:E52-4.

9. Seyama I, Yamada K, Kato R, Masutani T, Hamada M. Grayanotoxin opens Na channels from inside the squid axonal membrane. Biophys J. 1988;53:271-4.

10. Yuki T, Yamaoka K, Yakehiro M, Seyama I. State-dependent action of grayanotoxin I on $\mathrm{Na}(+)$ channels in frog ventricular myocytes. J Physiol. 2001;534:777-90.
11. H. C. Bazett, "An Analysis of the Time-Relations of Electrocardiograms," Heart 1920;7:353370.

12. Yaylacı S, Osken A, Aydın E, Genç A, Demir M, Kocayiğit İ, et al. Deli Bal Zehirlenmeleri Genel Özellikler, Ulusal ve Uluslararası Literatürün Incelenmesi. Journal of Human Rhythm 2015;1:139-142

13. Kolecki PF, Curry SC. Poisoning by sodium channel blocking agents. Crit Care Clin. 1997; 13:829-48

14. Choi HL, Park KH, Park JS, Choi HY, Kim H, Kim SM. Relationship between blood toxin level and clinical features in patients with grayanotoxin poisoning - six clinical cases. Clin Toxicol (Phila). 2017;55:991-995.

15. Zitron E, Scholz E, Owen RW, Lück S, Kiesecker C, Thomas D, et al. QTc prolongation by grapefruit juice and its potential pharmacological basis: HERG channel blockade by flavonoids. Circulation. 2005;111:835-8.

16. Aslan S, Cakir Z, Emet M, Aksakal E, Akoz A, Uzkeser M. Wildflower (Hyoscyamus reticulatus) causes QT prolongation. Bratisl Lek Listy. 2013;114:333-6.

17. 1Sayin MR, Dogan SM, Aydin M, Karabag T. Extreme QT interval prolongation caused by mad honey consumption. Can J Cardiol. 2011;27:870.e17-9.

18. Yates C, Manini AF. Utility of the electrocardiogram in drug overdose and poisoning: theoretical considerations and clinical implications. Curr Cardiol Rev. 2012;8:137-151.

19. Shannon $M W$. Duration of $Q R S$ disturbances after severe tricyclic antidepressant intoxication. J Toxicol Clin Toxicol. 1992;30:377-86. 